Cewa. In addition to a contribution to a book on Nsenga puberty ritual, a paper on Nsenga music is planned, as well as the publication of three long-playing gramophone records.

(Communicated by Mr. John Blacking and Dr. Raymond Apthorpe)

\title{
Exhibition of Sierra Leone Crafts in London
}

AN exhibition of Sierra Leone masks, carvings, and crafts was held in London during August at the Commonwealth Institute. A large number of ceremonial masks and figures, used in the Sande, Yassi, and other associations of the Mende and Bullom peoples, were shown; other exhibits included carved nomoli figures and Warri boards, musical instruments, carved canoes, and country cloth. All the exhibits were the property of Mr. Guy MassieTaylor, lecturer in art at Freetown Training College.

\section{A Comparative Ecological Field Research Programme in East Africa}

A CO-ORDINATED analytical study of the relation between ecology and social and cultural patterns has been initiated in East Africa under the direction of Professor Walter Goldschmidt of the University of California, Los Angeles. The research involves a detailed investigation of the internal variation within four separate tribes, each of which occupies a territory with diverse geographical character, and in each of which there is one sector predominantly engaged in pastoralism and another sector engaged in the cultivation of crops.

An ethnographer will be resident among each of the peoples studied: Dr. E. V. Winans, Assistant Professor of Anthropology at the University of California, Riverside (and Assistant Director of the Project), is studying the Hehe of Tanganyika; Dr. Francis P. Conant, Assistant Professor at the University of Massachusetts, is among the Suk (Pokot) of Kenya; Dr. S. Chadwick Oliver, Assistant Professor at the University of Texas, is studying the Kamba of Kenya, while Professor Goldschmidt is returning for further study of the Sebei of Uganda. In addition to standard ethnographic investigations among both the pastoral and farming sectors of the respective tribes, the ethnographers will collect demographic and economic data from a sample of the population in each area.

Information on the landscape, on the environmental potential, and on land use will be obtained from all four tribes by Dr. Philip W. Porter, Assistant Professor of Geography at the University of Minnesota.

Social attitudes, values, and psychological orientation will be studied by Dr. Robert B. Edgerton, Research Assistant of the Institute of Neuropsychiatry, University of California, Los Angeles, who is administering a battery of questionnaires and tests to samples of each population.

The purpose of the study is to examine the cultural adjustments to the underlying economic mode in each of the tribes, and to determine whether certain expected shifts in social life consistently take place. The programme stems from the theoretical consideration of the relation between socio-cultural behaviour and economic life-modes, and the broader problems of cultural evolution, as developed by the Director of the Project in his recent book, Man's Way, A Preface to the Understanding of Human Society (British edition: Understanding Human Society, Routledge and Kegan Paul). The research is supported by grants from the National Science Foundation and the National Institute of Mental Health, both agencies of the United States Government. Field work began during the summer of $196 \mathrm{I}$ and will continue until the autumn of 1962.

(Communicated by Professor Walter Goldschmidt)

[See also p. 37.] 